\title{
Chapter 9 \\ Building Resilience in Young Children the Sesame Street Way
}

\author{
Geraldine V. Oades-Sese, David Cohen, Jedediah W.P. Allen, \\ and Michael Lewis
}

\section{Theoretical and Research Bases}

\section{Resilience in Young Children}

Young children face many challenges in their daily lives and are also directly affected by stressful life situations that their families may experience. These challenges can vary in level of severity and in location within the bioecological system of a child's environment-each of which differentially impacts development (Bronfenbrenner, 2005). At the child level, these challenges include learning how to master a skill such as tying shoes or writing the letters of their name, to the more interpersonal challenges of developing friendships or resolving conflicts with peers. At the family level, some children are faced with more stressful situations such as inconsistent parenting, financial instability, divorce, or the incarceration of a parent. At the community level, some children live in unsafe neighborhoods and attend poor quality schools. More distal challenges that affect development involve institutionalized prejudice, cultural incongruence, disparities in healthcare or access to healthy foods (see Garcia Coll et al., 1996). Regardless of which level(s) these challenges stem from, challenges at any level impact other levels of a child's environment bidirectionally and tend to initiate a rippling effect (Bronfenbrenner \& Morris, 2006). These well-known proximal and distal risk factors are associated with negative developmental outcomes. Despite the challenges children encounter, however,

G.V. Oades-Sese $(\varangle) \bullet$ J.W.P. Allen $\bullet$ M. Lewis

Department of Psychology, Bilkent University, Ankara, Turkey

e-mail: sesege@rwjms.rutgers.edu

D. Cohen

Sesame Street Workshop, New York, NY, USA 
normally developing children are resilient or have the capacity to overcome these adversities and succeed (Masten, Best, \& Garmezy, 1990).

Protective factors are those that promote resilience and originate from multiple sources found within the child, the family, and the community. These protective factors are essential ingredients for mitigating the risk factors mentioned above and for building physical and mental health, emotional well-being, social relationships, and academic achievement. Masten and Garmezy's (1985) “immunity-versus-vulnerability" or the protective factors model is a theoretical model which suggests that certain personal attributes can either "dampen or amplify" the impact of stress. The more protective factors children have the better they are able to cope with life stressors.

Research studies document a number of protective factors in children which include average or better intelligence, social competence, emotion regulation, an internal locus of control, and a sense of self-worth (Masten et al., 1990; Oades-Sese, Esquivel, Kaliski, \& Maniatis, 2011; Rutter, 1990; Werner \& Smith, 1992). Similar protective factors have been identified in economically disadvantaged children faced with significant barriers to success such as peer pressure, discrimination, and prejudice (Ford, 1994). Furthermore, determination, motivation, inner will, independence, realistic aspirations, and a heightened sensitivity to others and the world around them were also identified as crucial protective factors in children (Reis, Colbert, \& Herbert, 2005).

In families, resilience is evidenced by close nurturing relationships that provide emotional support and positive and open communication between family members (McCubbin \& McCubbin, 1996). Families who set high expectations, provide routines, and instill core values are likely to foster resilience in children (Seccombe, 2002). Furthermore, trusting and supportive family relationships are the foundations from which these essential child-level protective factors develop (Orthner, Jones-Sanpei, \& Williamson, 2004; Werner \& Smith, 1989).

Protective factors that originate from the community include having access to basic needs (i.e., clean air and water, food, adequate housing) safe neighborhoods as well as equitable public policies that determine who is or is not eligible to receive benefits and services. Community resources that offer support to children and their families confronted with stressful life situations are key to building resilient families. Community partnerships, in particular, comprised of families, schools, and organizations help families combat adversity and systemic barriers in the community (Epstein \& Sanders, 2000). Sesame Workshop is one such organization involved with community outreach to support the educational needs of children and foster healthy and strong families.

In sum, challenges and stress are part of young children's lives and the better they are equipped to deal with these challenges, the more likely they are to succeed. Building protective factors within the child, family, and the community is essential in developing healthy and productive individuals who make lifelong contributions to society.

\section{Learning as Active Engagement}

From our developmental perspective, the ability to be resilient is not innately given to some and not to others-with adequate guidance and support, every child has the 
capacity to become resilient. If development is generally understood as a matter of children learning about how to learn (Bickhard, 2007), then such "meta-learning" is what enables children to successfully adapt to changing situational and environmental circumstances. In turn, the possibility of meta-learning means that children can learn to become resilient. There are two general orientations that try to explain how learning comes about that correspond to two general perspectives on the nature of knowledge (Allen \& Bickhard, 2011). For the first, knowledge is fundamentally passive and learning is a matter of having the world "impress" itself into the mind. For the second, knowledge is fundamentally active and learning is a matter of having to "construct" how to successfully interact with the world. While the former view is dominant in contemporary developmental psychology (Allen \& Bickhard, 2013), the latter view is more common in educational scholarship with its most thorough development by Piaget (1954). For Piaget, knowledge was emergent from action and therefore children needed to actively explore their environment in order to learn about the world. Although direct action on the world becomes less relevant as children develop through the preschool years, the active and constructive nature of learning remains essential.

Taking the active and constructive nature of learning seriously means recognizing that, ultimately, it is the child who must do the learning-it is the child who must create the "new" knowledge for themselves. Consequently, if learning is both an effortful and creative process, then there are two major components involved with facilitating such learning. The effortful part implies the need for motivation and the creative part implies generating something that is cognitively new. While a child's motivation to learn can be harnessed through multiple methods, the crucial point is whether or not what they are learning is interesting to them. Perhaps, the easiest way to generate interest for preschoolers is through game-like activities that involve interactions with other people. While not everything that a child needs to learn can be made fun, when boring "facts" are learned in the service of developing new abilities, we find that children are more than willing participants. That is, fun activities can be supplemented by harnessing children's intrinsic motivation to expand their own agency. Intrinsic motivation for agency is most evident in infancy when the child must learn to coordinate actions in order to achieve a goal (e.g., grabbing an object) but that agentive motivation is present throughout development (e.g., preschoolers who try to help their parents with household chores).

Our approach towards pedagogy places the locus of control within the child who is engaged in the process of learning. Accordingly, our role as educators is not to transfer information into empty and passive receptacles, but rather, to guide, constrain, and enable (i.e., scaffold) the generative activity of the child as they explore and integrate their understanding of new information with what they have already learned. The particular path that a child takes on their way to understanding new concepts will be unique and that is part of the reason that genuine learning is so difficult. Consequently, it is important to find different mediums and situations that will fit the needs of different types of learners. Further, given that knowledge and understanding comes in degrees, it is important for a pedagogical approach to find ways to challenge a child's current understanding so that they might develop a deeper and broader appreciation of what is to be learned. One of the best ways to 
accomplish this is to provide situations where children are able to use their new knowledge across a broad range of contexts and situations.

Consistent with our active and constructivist approach towards learning, Sesame Street provides children with a number of avenues to learn basic concepts essential for school readiness. Through the use of songs, television and video, storybooks, play dolls, coloring books, and other materials, Sesame Street provides children with a smorgasbord of resources from which to learn. The multiple contexts and settings in which content is available for children to explore new ideas enables them to actively construct an integrated understanding of the material. Further, Sesame Street materials are fun and engaging which means that children are motivated to learn about the content while also developing their social and emotional competencies. Many of the Sesame Street activities are social in nature which provides opportunities for children to engage in meaningful social interactions. In addition, the world of Sesame Street and its lovable characters are a part of our commonly shared culture. This commonality provides opportunities for children and adults to participate in social realities that extend beyond any particular interaction. In short, Sesame Street provides children with both the opportunity and motivation to learn new content while also developing their ability as social participants.

\section{Role of Emotions in Learning}

An important factor that needs to be addressed in relation to intrinsic motivation is the role of emotions in children's learning (Oades-Sese, Matthews, \& Lewis, 2014). Emotions are fundamentally important in cognitive processes that contribute to how we learn such as perception, attention, memory, decision-making, and problemsolving skills (Clore \& Huntsinger, 2007; Pekrun, 2011). Positive emotions such as enjoyment of learning and pride have been linked to intrinsic motivation and interest in students across all ages, while negative emotions such as anxiety, shame, and boredom can hamper students' motivation to learn and affect their performance (Pekrun, 2011). While children's experiences in school have an effect on their emotions and performance, experiences at home with parents are also important. Parents, after all, are not only the initial determiners of children's achievement behavior (Center on Social Emotional Intervention for Young Children \& Eccles, 1997), but they are also important in terms of children's emotional life which affect their academic performance. Parental behaviors, specifically verbal comments about children's behaviors, are likely to have a long-term impact on how children orient to learning tasks and respond to success or failure (Alessandri \& Lewis, 1996; Lewis, 1992). A positive sense of self develops when parent-child interactions are positive and reaffirming (Kaufman, 1992). Specifically, verbal comments that refer to acknowledgement of effort, strategy, and persistence may allow for a fuller recognition of achievement, which leads towards a mastery orientation. This is in contrast to verbal comments that focus on the global self such as "You are smart!" This is important in terms of when failures and successes occur in daily life. When failure is due to lack of effort or poor strategy, children are able to recover from failure by 
putting more effort or applying a better strategy (Oades-Sese et al., 2014). This is in contrast to children who blame themselves (I am dumb) for the failure. In this instance, children feel helpless because of their belief that they inherently lack the cognitive capacity to succeed. Furthermore, this can be applied to verbal comments provided by teachers in schools. Therefore, interventions that focus on building positive and nurturing parent-child or teacher-child relationships and communications, fostering positive emotions, and providing problem-solving strategies (i.e., ask for help, try again, study more) that children can use when faced with daily or life challenges are essential tools in building resilience and academic success.

\section{Sesame Street's Little Children, Big Challenges Initiative}

One of theinitiatives that the Educational Outreach department at Sesame Workshop embarked upon was to help build strong and healthy families. The resilience initiative provides families and their young children (ages 5-8) with the tools and resources necessary to overcome everyday challenges, transitions, and stressful life events. These tools and resources maximize the use of multimedia and technology and showcase the lovable Muppets of Sesame Street in various scenarios and specific experiences relevant to military and civilian families. These resources include print and online materials (e.g., parent guides, educator's guide, storybooks) for primary caregivers and child care providers of young children with information and activities, digital media (apps), and a Sesame Street DVD for caregivers and children to view together. The content of the materials, developed with the help of an advisory panel and focus groups, targets the fundamental skills necessary to overcome challenges faced at home, school, and in the community. The materials focus on the core competencies of expressing and managing feelings, coping with frustration, building a self-concept, developing problem-solving skills, and fostering perseverance (Brooks \& Goldstein, 2001; Eiesnberg et al., 1997; Greenberg, 2006; Masten, 1994).

The goals of Little Children, Big Challenges are to:

- Foster children's core competencies and model effective ways for young children to confront both difficult everyday situations and challenging circumstances by drawing on these skills (e.g., videos of the Sesame Street characters modeling the appropriate problem-solving steps of "breath, think, do").

- Help parents, caregivers, educators, and other professionals by providing specific activities and ways on how to communicate with their young child and thereby foster resilience skills that will equip children to effectively express emotions, develop empathy for others, confront setbacks, solve problems, have a positive sense of self, and persevere.

- Provide support and resources to help children and families cope with the uniquely challenging situations of bullying, divorce, relocation, and incarceration of a parent as well as to help educators build resilience skills in children to deal effectively with challenging situations that occur in school. For example, showing children how drawing or writing letters can maintain contact with an incarcerated parent. 
By providing the community (i.e., parents, teachers, caregivers, educators, professionals) with these necessary tools and resources, Sesame Workshop is able to contribute to and foster the successful development of children.

\section{Brief History of Sesame Street}

Conceived in the 1960s during Lyndon Johnson's "War on Poverty," Sesame Street was designed as an experiment to test whether or not an entertaining television show could be used as a tool to educate young children. The specific aim of the show was to help children from low-income families prepare for school. Today, Sesame Street, with its beloved Muppet characters, has aired in over 140 countries, and has expanded beyond television to include books, radio, interactive and online media, and community outreach initiatives. As some have noted, Sesame Street has evolved into "the longest street in the world."

As it turns out, the founders were right - the experiment worked. Evidence from several early evaluations indicated that Sesame Street viewers outperformed their non-viewing peers on a range of cognitive, academic, and socio-emotional measures (Wright et al., 2001). In particular, longitudinal studies have also shown that children who were frequent Sesame Street viewers at age two scored higher on standardized tests of school readiness in kindergarten than less-frequent or nonviewers and that frequent Sesame Street viewing in preschool is associated with higher high-school grade point averages even when controlling for several demographic factors (Anderson, Huston, Schmitt, Linebarger, \& Wright, 2001). One recent study found that children in preschool classrooms, which participated in a media-rich curriculum incorporating public television video and games (from Sesame Street, Super Why and Between the Lions), developed the early literacy skills critical for success in school. These foundational skills-being able to name letters, knowing the sounds associated with those letters, and understanding basic concepts about stories and print-all increased among the 4- and 5-year-olds in the study (Penuel et al., 2012). Other studies have found that children who viewed Sesame Street segments also had the highest level of prosocial behaviors during planned and structured activities and were lowest in antisocial behaviors during free play (Zielinska \& Chambers, 1995).

\section{Community Outreach}

The Educational Outreach department within Sesame Workshop has been especially instrumental in the development and distribution of content, particularly to lowincome families. The Educational Outreach department is able to specifically meet the needs of families with young children with the greatest need by getting resources into the hands of these families, working with these families and advisors (i.e., policy makers, educators, developmental psychologists) during the development of 
resources to determine issues of particular urgency and to ensure resources are appealing, useful, and relevant. Effectively and directly reaching families and children in need is accomplished in part by involving key national organizations as the resources are being developed, thereby ensuring that the resources can be easily integrated into these organizations' delivery systems (Sesame Workshop, 1983).

During Sesame Workshop's early years, the primary goal of Educational Outreach (then called "Community Education Services") was to raise awareness among low-income and underserved families in inner-city neighborhoods and rural America about the educational value of Sesame Street, and instruct these families on how they could make the most out of the Sesame Street viewing experience. This task was accomplished at a community-based grassroots level, through house-tohouse canvassing, trainings at Head Start programs and other publicly funded child care programs, and workshops at parent-teacher meetings, community events, church groups, and other neighborhood programs.

Once Sesame Street became better known as a positive addition to children's daily television fare, Educational Outreach shifted its focus from solely building viewership to utilizing the resources at Sesame Workshop to engage in topic areas and initiatives addressing the needs of families and children experiencing the effects of ongoing poverty. These initiatives also reached out to child care providers to use these outreach materials as a springboard for hands-on and other activities that addressed children's cognitive, health, and/or social and emotional development, as well as family engagement in their children's overall well-being. Additionally, training programs served to introduce providers to the outreach resources, and furnished support for integrating these resources as a vital tool for their programs (Yotive \& Fisch, 2001).

Outreach efforts to reach children in need, wherever they may reside, led to initiatives in some unexpected settings. For example, outreach initiatives were created for migrant camps, which allowed providers to incorporate Sesame Street materials into their curricula while the children's parents worked as migrant laborers in nearby fields. Sesame Street centers were established in federal prisons to provide facilities in which young children could engage in songs, games, and other educational activities while their parents visited relatives who were incarcerated (Yotive \& Fisch, 2001).

Educational Outreach continues to create needs-driven public service initiatives across multiple media platforms, leveraging relationships and distributing materials through a network of strategic partnerships in the United States and around the world. As before, outreach initiatives are driven by local needs and urgencies. Most outreach programs and the materials produced for them stem from Sesame Street or its international variations, making creative use of the Sesame Street characters, formats, and educational curricula. Most domestic projects are produced in both English and Spanish (and, in some additional languages, such as Mandarin and Arabic), in order to obtain maximum reach. Materials developed for the various initiatives are distributed free of charge through a wide domestic and international network of organizations that reach into the community via schools, child care programs, libraries, public television stations, health care programs, literacy programs, ethnic advocacy organizations, and other groups that serve children and families. 
The success of the Workshop's content and initiatives is often credited to the synergy of a variety of expertise and an iterative feedback process. To set goals, establish curricula, and monitor the impact of their projects, Sesame Workshop's founders created (the "Sesame Workshop Model") involving a dynamic collaboration among educators, researchers, and media producers (Mielke, 1990). A project typically begins with a series of advisory panels, which are gathered to develop the educational goals for a particular project, followed by a period of time in which educators write curricula based on these goals. These curricula are then used by writers and producers as a guide when creating the program or content. An integral part of this model is the formative research process. Formative research usually begins by conducting needs assessments examining current research being conducted with children and families around the curriculum topic being explored, and conducting research with children and families to gauge the extent of their knowledge of the curriculum topic. This phase aids writers and producers on how to approach the educational goals, determining which goals are of greatest importance, and how the educational content should be best presented. Once drafts of print or video materials are available, they are presented to children (and/or their caregivers if they are also the intended audience) to gauge comprehension and appeal. The feedback from children and caregivers is then used to inform any changes before the final production of content. Finally, an evaluation may be conducted to assess whether the content has the desired impact.

\section{Role of Muppets}

\section{Role of Puppets/Muppets in Intervention Design}

Puppets have been a part of human history since ancient times as means of selfexpression (Esquivel, Oades-Sese, \& Jarvis, 2010). In Ancient Egypt, puppets were jointed and made from terracotta, while shadow puppets in China were made of rod and animal skin. In Turkey, they were three-dimensional and articulated to reflect the natural movements of people. Puppets (e.g., sock puppets, marionettes, hand puppets) have evolved and made their way into public television with Howdy Doody; Kukla, Fran, and Ollie; Sherlock from the Magic Garden; Lamb Chop; Mr. Rogers' King Friday XIII, Lady Elaine Fairchilde, and Henrietta Pussycat; Jim Henson's Kermit and Miss Piggy to the lovable Sesame Street characters of Elmo, Grover, Oscar the Grouch, Rosita, Count von Count, and many more.

Although the research literature is sparse, the use of puppets has been widely documented to be effective in a variety of clinical applications and interventions. For example, puppets were found to help hospitalized children cope with illness and separation from parents (Woltmann, 1940) and to help abused or traumatized children feel more comfortable to play out their experiences than interacting directly with a therapist. This is similar to the spontaneous way children use family dolls or action figures to play out their thoughts, feelings, anxiety, and fears (Carter, 1987; Seinfeld, 1989). Children identify with puppets and project their feelings onto them. This allows children to depersonalize their feelings and share them indirectly with a therapist. 
Puppets that reflect or represent cultural values and traditions are shown to be more effective for children, especially for children from culturally and linguistically diverse backgrounds. For example, because Native Americans value storytelling and humor, clown-like figures are often found in their folklore. Fables and fairytales across cultures often feature animal characters that teach a lesson or feature positive or negative traits. Therefore, animal puppets are often used during storytelling with children (Herring \& Meggert, 1994). In the educational and clinical setting, multicultural puppets can be very effective in teaching children about feelings, emotional literacy, conflict resolution, and prosocial skills (Esquivel et al., 2010).

In the field, the first author has found puppets "of color" useful in training teachers how to teach preschool children conflict resolution or problem-solving skills in their classrooms; both teachers and children are often more engaged and motivated to learn. Multicultural puppets are also used to teach children about acceptance and tolerance for differences. The "Kids on the Block" puppet program (Aiello, 1988) is an example that teaches nondisabled children to understand and appreciate those who with physical and/or mental challenges. Puppets can also be used to represent a variety of health conditions, disabilities, or situations such as cerebral palsy, mental retardation, learning problems, parental incarceration, and divorce.

Many evidence-based interventions in early childhood incorporate puppets to build social skills, emotional understanding, interpersonal problem-solving skills, and literacy (Dunlap \& Powell, 2009). Examples of these interventions include Al's Pals (Wingspan, 1999), Incredible Years: Dina Dinosaur Classroom Curriculum (Webster-Stratton, 2002), Preschool PATHS (Domitrovich, Greenberg, Kusche, \& Cortes, 2004), Second Step (Committee for Children, 1991), and Preschool I Can Problem Solve (Shure, 2000). Use of puppets in an intervention ensures sustained interest, active engagement, and provides a medium to externalize and objectify feelings and difficult life situations.

\section{Sesame Street Muppets}

Sesame Street's Muppets have been delighting children for decades. Muppets have been instrumental in helping Sesame Workshop engage and teach children in different curriculum areas and countries. The Muppets make it possible to introduce sensitive subjects, the one that may be deemed too sensitive to attempt with young children in a video or television show. Their versatility and diversity enable these characters to broach difficult or complex topics, such as divorce or death of a loved one, in age appropriate ways that help preschoolers to cope.

Initially conceived as a way to help maintain children's attention to the curriculum goals that Sesame Street was trying to teach, the Muppets were an ideal tool for engaging children and conveying information. Muppets could consistently remain in character across episodes and also were able to portray more exaggerated and clearer roles than human characters (Lesser, 1974). Their physical design, of softer materials such as foam, enables these puppets to be more expressive than traditional puppets. Their eyes and face are constructed in a unique fashion, to form a "magic 
triangle," whereby pupil's of the Muppet's eyes focus slightly inwards, creating a triangle with the Muppet's nose. This positioning of the pupils, combined with the curvature of the face makes the Muppet appear to be focusing directly on the camera and the children watching (Gikow, 2009). These unique qualities, as well as their familiarity allow the Sesame Street Muppets to speak to children in ways that otherwise might not be possible. Through their endearing personalities and their particular appearance, they have been able to teach children all over the world about tolerance, literacy, health and hygiene, and self-esteem.

\section{Multimedia and Technology}

\section{Role of Multimedia Technology}

In general, multimedia and technology approaches to education are well suited to a constructivist perspective on learning (Mayer, Moreno, Boire, \& Vagge, 1999). Multimedia and technology approaches do not just repeat the same information in different formats, like Morse code and the alphabet, but rather, the multiple modes of presentation provide unique information that can converge to enable a more comprehensive and a more thoroughly integrated understanding of the content. In the past, technology-based interventions tended to mean using computers-both for the presentation of material and for student-guided learning (Ringstaff \& Kelley, 2002). The widespread availability of the Internet starting in the mid 1990s transformed the educational use of computers into a resource that is much more dynamic, interactive, and multipurpose than "stand-alone drill-and-practice" systems (Waxman, Lin, \& Michko, 2003). The current ensemble of multimedia devices available for use in the classroom has further expanded the scope and depth of technology-based interventions.

Multimedia environments can be broadly defined as communications involving multiple modes of presentation. In the simplest case, theses modes of presentation can include different modalities as with the combination of visual and verbal formats in a narrated film. More sophisticated multimedia environments, however, are also going to include some degree of interactivity with both the materials and with other people. For example, the turn-taking involved with learning a new song or game or reading a new storybook. From our perspective, what is most important about a multimedia environment is that there are a variety of ways in which different aspects of the content can be presented and the degree to which children are encouraged to actively engage with such content either directly or indirectly with other people.

Sesame Workshop capitalizes on multimedia and technology through television, DVDs, mobile apps, and Internet resources, but it also utilizes storybooks and activities that involve interactions with other people. Sesame Workshop's use of a multimedia approach is well suited to capitalize on both the cognitive and motivational aspects of learning. Cognitively, using a multimedia approach means that we are able to accommodate many of the individual differences in the learning styles of children, while also reinforcing different aspects of the same basic content across multiple contexts. Motivationally, the inherent appeal of the Muppet characters and 
the interest children have in using various forms of technology helps them attend to, and engage with, the content of the material being presented. Further, past research has found that less formal presentation styles are better able to promote learning in multimedia environments (Moreno \& Mayer, 2007) —a feature that is exemplified by the friendly and conversational presentation style of the Muppet characters.

\section{Effectiveness of Technology-Based Interventions}

Evaluating the effectiveness of technology-based interventions in the classroom is difficult given the large variability in both the purposes of the interventions and the multiple varieties of implementations (Cook, Garside, Levinson, Dupras, \& Montori, 2010). While not all technology-based interventions are effective at showing gains relative to control groups, there does not seem to be any negative effects from such research. This is important because optimizing interventions requires determining what does not work as much as it involves figuring out what does work. Further, there does not seem to be any "silver bullet" intervention principles or techniques that will apply across all contexts and for all purposes. Thus, research that has ruled out intervention principles and techniques in one area may be safely studied in another area without negatively impacting children's education.

The effect of multimedia-enhanced educational instruction on the vocabulary growth of young children has been mixed for both native English speakers and for English Language Learners (Silverman \& Hines, 2009). What does seem to be clear is that viewing education television in the classroom without additional elaboration or reinforcement does not provide gains in vocabulary growth for either native English speakers or for Spanish-English bilinguals (Linebarger, Kosanic, Greenwood, \& Doku, 2004; Uchikoshi, 2006). Therefore, the use of multimedia in the classroom in conjunction with teacher interaction, guidance, and feedback are essential in order to realize the promise of multimedia learning environments.

We are currently assessing whether the Little Children, Big Challenges DVDs, mobile apps, and Internet resources are being utilized by parents and teachers and whether these multimedia resources are effective in building close parent-child relationships, emotional knowledge and understanding, emotional literacy, and problem-solving skills. We are also evaluating whether these resources help children and their families better prepare for future challenges.

\section{Resilience-Based Intervention}

\section{Theory of Change}

The Theory of Change plays an important role in intervention development and provides a visual representation of the pathway to change. It provides a roadmap to achieve the goal(s) of the intervention and charts out destinations of progress. 


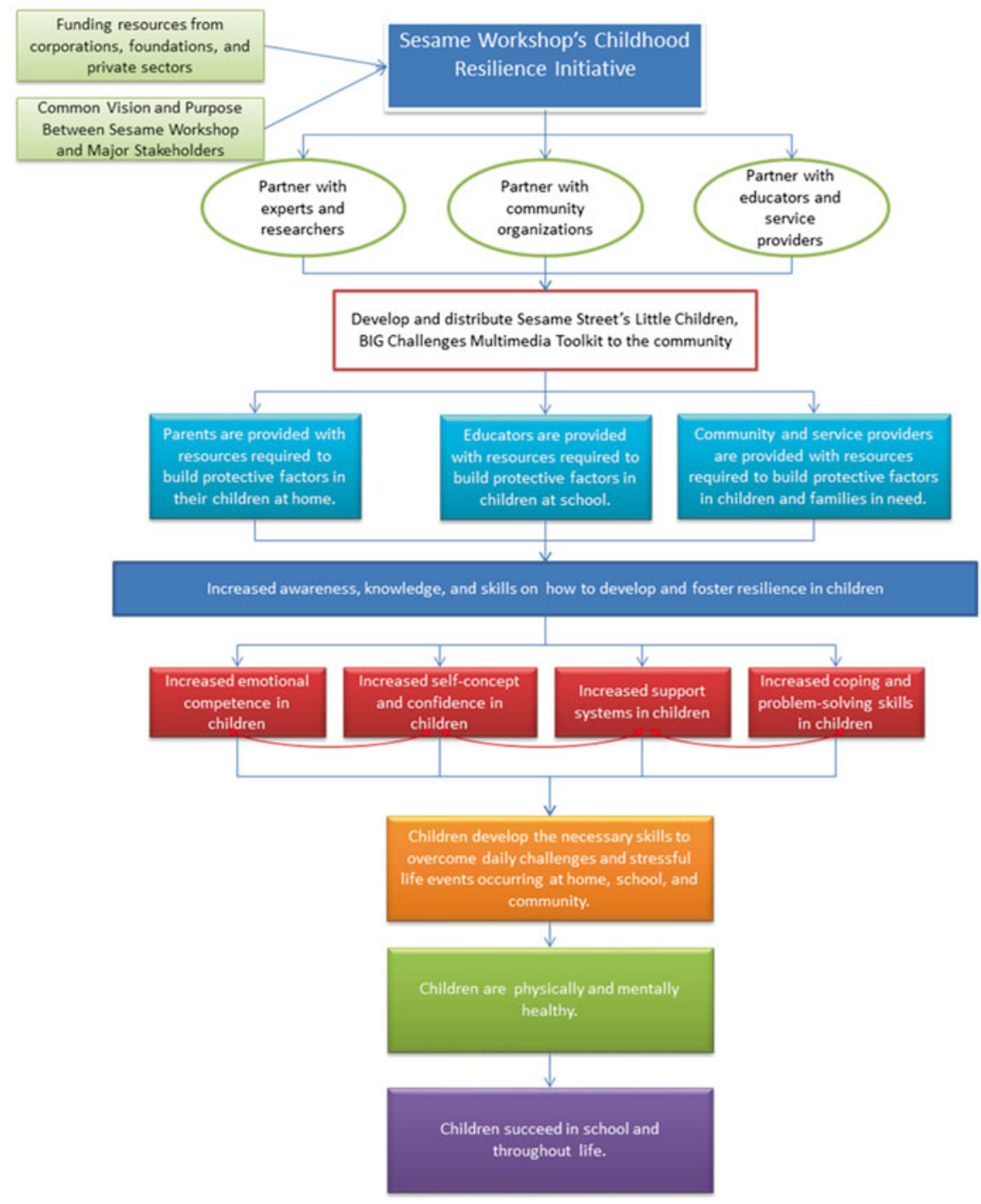

Fig. 9.1 Theory of change for the Sesame Workshop's childhood resilience initiative

The Theory of Change visual diagram (see Fig. 9.1) depicts the Childhood Resilience Initiative strategies and intended results. Partnerships with researchers, experts, community organizations, educators, and service providers are key ingredients to developing and disseminating the intervention. The short-term goals of the initiative are to (a) empower adults who are significant in children's lives (i.e., parents, caregivers, educators) by increasing their awareness and knowledge about the protective factors that underlie resilience, (b) provide these adults and the community with 
free and accessible resources to develop the skills for "how" to promote resilience in multiple contexts, and, (c) improve the attitudes, behaviors, and skills that are necessary for children to overcome challenging situations. Successful achievement of these short-term goals should lead to the long-term goal of building strong, healthy, and successful children.

The assumptions that underlie the initiative's Theory of Change influence the road-map's design. These assumptions are as follows:

- Research is a valuable source of information that contributes to the design and development of an intervention.

- Expertise and leaders, at multiple levels in the community, help define and identify important protective factors that underlie resilience in young children.

- Multimedia and technology are able to engage learners with different learning styles, abilities, and cultural backgrounds.

- By providing the necessary tools to primary caregivers, they are more likely to be successful in building healthy and resilient children.

- Well-designed program evaluation increases learning and development for future projects and influences the effectiveness of the funders' investments.

\section{Little Children, Big Challenges Multimedia Toolkits}

There are three multimedia toolkits that were developed by Sesame Workshop as part of the Little Children, Big Challenges initiative. While two of them are focused on the specific life challenges of divorce (Little Children, Big Challenges: Divorce) and incarceration (Little Children, Big Challenges: Incarceration), the third multimedia toolkit (Little Children, Big Challenges: General Resilience) is focused on building general resilience for dealing with life's more day-to-day challenges at home and school. The divorce and incarceration toolkits were designed to be used by parents at home and the general resilience toolkit was designed to be used by preschool teachers in the classroom and by parents at home. Based on the recommendations of the initiative's advisory board, four protective factors were emphasized in the toolkits: circle of care (attachment), sense of self, emotional understanding and knowledge, and problem-solving skills. These protective factors underlie social-emotional and academic resilience in young children.

The core of the two parent multimedia toolkits is a Sesame Street DVD, parent guidebook, and children's storybook. The Sesame Street DVD features a Muppet story and live-action films with real families sharing their experiences around some of life's challenging situations (e.g., divorce, incarceration of a parent). The Muppet story uses the familiar characters from Sesame Street to introduce young children to the type of challenging situation that is the focus of that particular toolkit. The primary purpose of the Muppet story is to help children understand what it means for their parents to be in the situation that they are in and that it is alright to have this difference from other families. In this way, the classic Muppet methodology is used to both explain the meaning of the challenging situation (i.e., divorce, incarceration) 
and to render any stigma about that type of situation inert. The parent guidebook has a number of tips and activities about how parents can engage with their children on the difficult topic that they are dealing with. For example, the parent guide addresses how to explain "divorce" or "incarceration" in developmentally appropriate ways. The storybooks include characters who are going through the same challenging situation as the child and provide parents with a natural setting to talk about their own situation as they read and reread the storybook with their children. For example, the storybook of the divorce/separation toolkit, Two-Hug Day, depicts Niko's experiences of going back and forth between the homes of his divorced parents.

The general resilience classroom toolkit is for use by preschool teachers in the classroom and includes a Sesame Street DVD featuring Muppet stories about dayto-day challenges that young children might face at school (e.g., saying goodbye at morning drop off, making new friends). The Muppet stories try to help children understand that these situations are a regular part of life and that they can learn strategies to help them gain some agency in the situation and resolve their discomfort. The general resilience toolkit also includes an education curriculum with 12 weeks of lessons and activities. The focus of the curriculum is on teaching children about different emotions beyond the basic ones (i.e., happy, sad, mad) and how to correctly identify and resolve interpersonal conflict situations. Children are taught to expand their emotion vocabulary to include words such as thrilled, ecstatic, disappointed, frustrated, furious, and miserable; and to use the steps of Breathe, Think, and Do to solve problems. There is also a parent version of this toolkit.

The different toolkits also make use of other multimedia materials that can be accessed through the Internet and specially designed mobile apps. Additional tips for parents and activities for children can be downloaded from the Internet. Webinars and online discussion sessions geared towards families and service providers are also available. Finally, Facebook pages have been created to help parents build a community of people who are all dealing with some of the same types of challenging issues. In sum, Little Children, Big Challenges includes multiple resources for helping children build resilience. The combination of both parent and teacher toolkits capitalizes on efforts aimed at a more holistic and comprehensive approach towards intervention research. These toolkits are made available free to parents, educators, and the community at www.sesamestreet.org. These toolkits can be used as a supplement to any social-emotional curriculum at school or used individually by parents with their children at home.

\section{The Role of Research, Accountability, and Impact Evaluation}

Research and outcome evaluations are important in determining the effect of an intervention. Findings from research can help make decisions about the future of interventions as well as serve as an accountability measure to determine if the funders' investments have been translated to effective social and educational interventions (Owen, 2007). Currently, we are conducting three research studies to determine the effectiveness of the Little Children, Big Challenges multimedia 


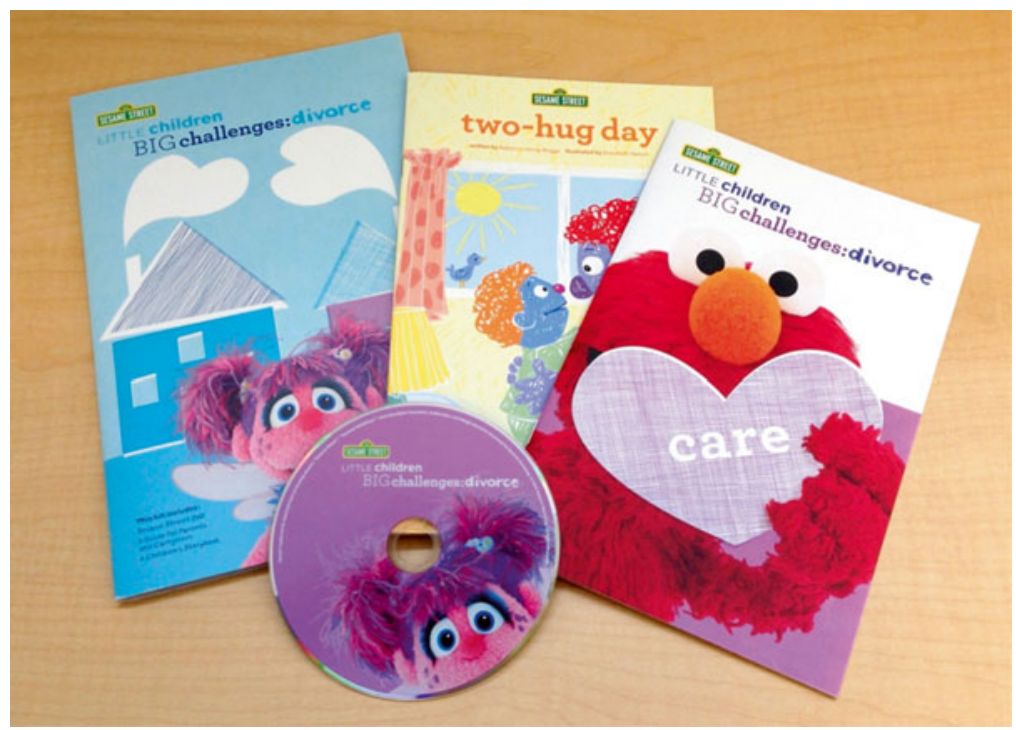

Fig. 9.2 Sesame Street's Little Children, Big Challenges: Divorce Toolkit

toolkits in building resilience in young children and their families. These studies include two parent intervention studies (i.e., Sesame Street Resilience Project: Divorce and Separation and Sesame Street Resilience Project: Families Dealing with an Incarcerated Parent) and a school-based intervention study (Sesame Street Resilience Project: General Resilience Classroom Study). The following paragraphs provide an overview of these studies.

\section{Building Resilience in Families Dealing with Divorce or Separation}

The purpose of the Sesame Street Resilience Project: Divorce and Separation is to determine the effectiveness of Sesame Street's multimedia toolkit, Little Children, Big Challenges: Divorce (see Fig. 9.2). The toolkit is designed to proactively help children build resilience factors during the challenging situation of divorce/separation. The aims of the toolkit are to: (a) provide children (ages 2-8) with the tools and language necessary to help them cope with and understand divorce at an ageappropriate level, (b) aid families in communicating and expressing feelings concerning the divorce, (c) teach children a feelings vocabulary, (d) provide parent tips such as managing strong emotions, dealing with blended families, and reducing stress, and (e) reassure children that they will be cared for, and that-together with their family - they can learn ways to adjust to their new life.

The Little Children, Big Challenges: Divorce toolkit fosters three key protective factors that include attachment relationships (circle of care), emotional 
understanding, and sense of self. These factors have been identified in the research literature and highlighted by Sesame Workshop because they summarize the main skills that are crucial in young children's development of resilience. These resilience factors are defined as follows:

- Circle of care is a network of secure attachment relationships that are crucial to children's emotional growth which include parents, teachers, relatives, and other trusted adults.

- Emotional understanding involves young children's ability to verbally label and express emotions via a feelings vocabulary, and to learn how to regulate and cope with emotions. In turn, these skills contribute to the development of empathy.

- Sense of self concerns young children's self-awareness of what they can and cannot do (abilities), their likes and dislikes, and personal characteristics. Children are able to develop self-confidence as they learn to value their unique qualities, to feel pride in their achievements, and to take on new challenges.

Participants in this 6-week study include 150 divorced or separated (civilian and military) parents and their children from diverse socioeconomic and ethnic backgrounds from New Jersey. Participants were recruited from over 70 preschools and Head Start centers and community organizations and randomly assigned to either the intervention or control group. The pre- and posttest study assesses parent satisfaction with and attitudes towards the toolkit, as well as their perceptions of the toolkit's impact on their child's developmental outcomes. We expect to find that the toolkit was effective in fostering parent-child relationships, communications about feelings surrounding the divorce or separation, and improved child behaviors.

\section{Building Resilience in Families with an Incarcerated Parent}

The purpose of the Sesame Street Resilience Project: Families Dealing with an Incarcerated Parent is to determine the effectiveness of Sesame Street's multimedia toolkit (English and Spanish versions)_Little Children, Big Challenges: Incarceration (see Fig. 9.3). The toolkit is designed to proactively help caregivers and children build resilience during the incarceration of a parent. The aims of the toolkit are to: (a) provide children (ages 6-8) with the tools and language necessary to help them cope with and understand incarceration at an age-appropriate level, (b) aid families in communicating and expressing feelings concerning the incarceration, (c) teach children a feelings vocabulary, (d) provide a parent or caregiver tips that are helpful regarding the incarceration, and (e) reassure children that they will be cared for, and that - together with their family - they can learn ways to adjust to their new life. Similar to the divorce and separation toolkit, the toolkit fosters three key protective factors that include attachment relationships (circle of care), emotional understanding, and sense of self.

Participants in this 6-week study include 100 parents or caregivers with young children who have an incarcerated parent from diverse socioeconomic and ethnic 


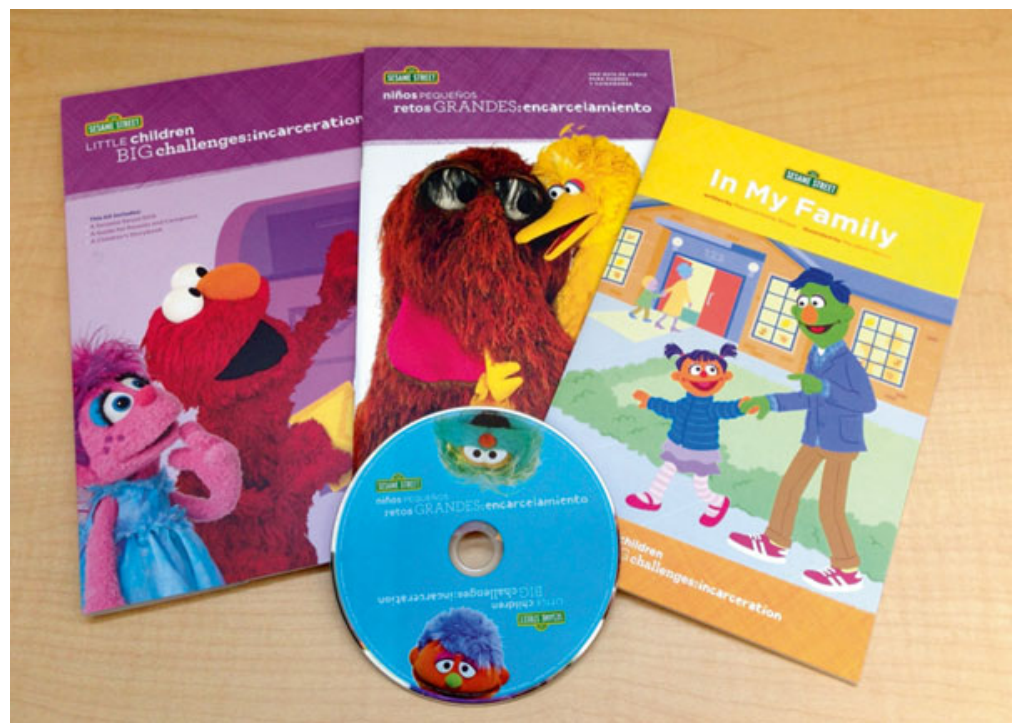

Fig. 9.3 Sesame Street's Little Children, Big Challenges: Incarceration Toolkit

backgrounds from New Jersey. Participants were recruited from over 70 preschools and Head Start centers, community organizations, and state prisons. Participants were randomly assigned to either the intervention or control group. The pre- and posttest study assesses parent satisfaction with and attitudes towards the toolkit, as well as their perceptions of the impact of the toolkit on their child's developmental outcomes. We expect to find that the toolkit was effective in educating parents and caregivers on how to cope with this stressful life situation, building parent- or caregiver-child relationships, communicating about feelings surrounding the incarceration of a parent, and improving child behaviors.

\section{Building Resilience in Schools}

The purpose of the Sesame Street Resilience Project: General Resilience Classroom Study is to determine the effectiveness of the multimedia toolkit, Little Children, Big Challenges: General Resilience. The aims of the toolkit are to: (a) provide teachers with the resources that they need to help children cope with and understand challenging situations at an age-appropriate level, (b) help children to communicate and express their feelings around challenging issues, (c) help children learn a feelings vocabulary, (d) foster the development of children's emotional competence in terms of their emotional understanding, emotional management and regulation, and interpersonal problem-solving skills. The Little Children, Big Challenges: General Resilience toolkit fosters four key protective factors that include circle of care, emotional understanding, sense of self, and problem-solving skills. 
Participants in this study include 700 children (ages 3-5), 700 parents, and 140 teachers from Head Start centers, state preschools, and military child development centers in San Diego, California. Participants are from diverse socioeconomic and ethnic backgrounds. Approximately, 50 schools were randomly assigned to either the intervention or control group. Teachers will be provided with a one-day training workshop to demonstrate how to implement the toolkit in the classroom as well as how to integrate the 10-15 min Sesame Street activities into their curriculum. The toolkit will be implemented daily for 12 weeks in 140 classrooms and two classroom fidelity checks will be conducted by trained research assistants. Pre- and postintervention data will be collected through direct assessment of randomly selected children in each classroom as well as parent data to determine if skills acquired in the classroom generalize to the home. Teachers' perceptions of children's socialemotional development as well as their attitudes, behaviors, and satisfaction regarding the toolkit will be evaluated. We expect to find that the Little Children, Big Challenges: General Resilience toolkit was effective in building children's emotional knowledge and understanding, emotional literacy, problem-solving skills, and social competence.

\section{Conclusion}

In closing, the overarching message that children and families learn from Little Children, Big Challenges is effectively communicated by Big Bird, Cookie Monster, and Elmo through a song created for the initiative called the "What We Are Anthem." The Youtube link is http://www.youtube.com/watch?v=FDWFT3VzOhw. Here is an excerpt of the anthem:

And nothing's gonna bring us down.

Never giving up.

Gotta go.

Because we know we'll keep getting stronger.

And what we are is helpful!

And what we are is brave!

What we are is thoughtful!

What we are is special!

What we are is confident!

There is nothing we cannot achieve because this is what we believe in...Because we know we'll keep getting stronger.

\section{References}

Aiello, B. (1988). The kids on the block and attitude change: A 10-year perspective. In H. Yuker (Ed.), Attitudes toward persons with disabilities (pp. 223-229). New York: Springer.

Alessandri, S. M., \& Lewis, M. (1996). Differences in pride and shame in maltreated and nonmaltreated preschoolers. Child Development, 67, 1857-1869. 
Allen, J. W. P., \& Bickhard, M. H. (2011). Emergent constructivism. Child Development Perspectives, 5, 164-165.

Allen, J. W. P., \& Bickhard, M. H. (2013). Stepping off the pendulum: Why only an action-based approach can transcend the nativist-empiricist debate. Cognitive Development, 28, 96-133.

Anderson, D. R., Huston, A. C., Schmitt, K. L., Linebarger, D. L., \& Wright, J. C. (2001). Early childhood television viewing and adolescent behavior. Monographs of the Society for Research in Child Development, 66, 1-143.

Bickhard, M. H. (2007). Learning is scaffolded construction. In D. W. Kritt \& L. T. Winegar (Eds.), Education and technology (pp. 73-88). New York: Rowman \& Littlefield.

Bronfenbrenner, U. (2005). Making human beings human: Bioecological perspectives on human development. Thousand Oaks, CA: Sage.

Bronfenbrenner, U., \& Morris, P. A. (2006). The bioecological model of human development. In W. Damon \& R. M. Lerner (Eds.), Handbook of child psychology, Vol. 1: Theoretical models of human development (6th ed., pp. 793-828). New York: Wiley.

Brooks, R., \& Goldstein, S. (2001). Raising resilient children: Fostering strength, hope, and optimism in your child. Lincolnwood, IL: Contemporary Books.

Carter, S. R. (1987). Use of puppets to treat traumatic grief: A case study. Elementary School Guidance and Counseling, 21(3), 210-215.

Center on Social Emotional Intervention for Young Children, \& Eccles, J. (1997). School and family effect on the ontogeny of children's interests, self perception, and activity choices. In J. Jacobs (Ed.), Nebraska symposium on motivation (Vol. 40, pp. 145-208). Lincoln, NE: University of Nebraska Press.

Clore, G. L., \& Huntsinger, J. R. (2007). How emotions inform judgment and regulate thought. Trends in Cognitive Science, 11, 393-399.

Committee for Children. (1991). Second step: A violence prevention curriculum. Preschoolkindergarten. Seattle, WA: Author.

Cook, D. A., Garside, S., Levinson, A. J., Dupras, D. M., \& Montori, V. M. (2010). What do we mean by web-based learning? A systematic review of the variability of interventions. Medical Education, 44, 765-774.

Domitrovich, C., Greenberg, M., Kusche, C., \& Cortes, R. (2004). PATHS preschool program. South Deerfield, MA: Channing Bete Company.

Dunlap, G., \& Powell, D. (2009). Promoting social behavior of young children in group settings: A summary of research. Roadmap to effective intervention practices \#3. Tampa, FL: University of South Florida, Technical Assistance Center on Social Emotional Intervention for Young Children.

Eiesnberg, N., Guthrie, I. K., Fabes, R. A., Reiser, M., Murphy, B., Holgren, R., et al. (1997). The relations of regulation and emotionality to resiliency and competent social functioning in elementary school children. Child Development, 68, 295-311.

Epstein, J. L., \& Sanders, M. G. (2000). Connecting home, school, and community: New directions for social research. In M. Hallinan (Ed.), Handbook of sociology and education (pp. 285-306). New York: Plenum.

Esquivel, G. B., Oades-Sese, G. V., \& Jarvis, M. L. (2010). Culturally sensitive narrative interventions for immigrant children and adolescents. New York: University Press of America.

Ford, D. (1994). Nurturing resilience in gifted Black youth. Roeper Review, 17, 80-85.

Garcia Coll, C., Lamberty, G., Jenkins, R., McAdoo, H., Crnic, K., Wasik, B., et al. (1996). An integrative model for the study of developmental competencies in minority children. Child Development, 67, 1891-1914.

Gikow, L. A. (2009). Sesame Street: A celebration of forty years of life on the street. New York: Black Dog \& Leventhal.

Greenberg, M. T. (2006). Promoting resilience in children and youth. Annals of the New York Academy of Sciences, 1094, 139-150.

Herring, R. D., \& Meggert, S. S. (1994). The use of humor as a counselor strategy with Native American Indian children. Elementary School Guidance and Counseling, 29(1), 67-76.

Kaufman, G. (1992). Shame: The power of caring (3rd ed.). New York: Schenkman Books. 
Lesser, G. S. (1974). Children and television: Lessons from Sesame Street. New York: Random House.

Lewis, M. (1992). The self in self-conscious emotions. A commentary. In D. Stipek, S. Recchia, \& S. McClintic (Eds.), Self-evaluation in young children. Monographs of the Society for Research in Child Development, 57, (1, Serial No. 226, pp. 85-95).

Linebarger, D. L., Kosanic, A. Z., Greenwood, C. R., \& Doku, N. S. (2004). Effects of viewing the television program Between the Lions on the emergent literacy of skills of young children. Journal of Educational Psychology, 96, 297-308.

Masten, A. (1994). Resilience in individual development: Successful adaptation despite risk and adversity. In M. Wang \& E. Gordon (Eds.), Risk and resilience in inner city America: Challenges and prospects (pp. 3-25). Hillsdale, NJ: Erlbaum.

Masten, A. S., Best, K., \& Garmezy, N. (1990). Resilience and development: Contributions from the study of children who overcome adversity. Development and Psychopathology, 2, 425-444.

Masten, A. S., \& Garmezy, N. (1985). Risk, vulnerability and protective factors in developmental psychopathology. In B. B. Lahey \& A. E. Kazdin (Eds.), Advances in clinical child psychology (Vol. 8, pp. 1-512). New York: Plenum.

Mayer, R. E., Moreno, R., Boire, M., \& Vagge, S. (1999). Maximizing constructivist learning from multimedia communications by minimizing cognitive load. Journal of Educational Psychology, 91, 638-643.

McCubbin, H. T. A., \& McCubbin, M. (1996). Family assessment: Resiliency, coping and adaptation-Inventories for research and practice. Madison, WI: University of Wisconsin.

Mielke, K. W. (1990). Research and development at the Children's Television Workshop. Educational Technology Research and Development, 38(4), 7-16.

Moreno, R., \& Mayer, R. E. (2007). Interactive multimodal learning environments: Special issue on interactive learning environments: Contemporary issues and trends. Educational Psychology Review, 19, 309-326.

Oades-Sese, G. V., Esquivel, G. B., Kaliski, P. K., \& Maniatis, L. (2011). A longitudinal study of the social and academic competence of economically disadvantaged bilingual preschool children. Developmental Psychology, 47(3), 747-764.

Oades-Sese, G. V., Matthews, T., \& Lewis, M. (2014). Shame and pride and their effects on student achievement. In R. Pekrun \& L. Linnenbrink-Garcia (Eds.), Handbook of emotions in education. New York: Taylor \& Francis.

Orthner, D., Jones-Sanpei, H., \& Williamson, S. (2004). The resilience and strengths of lowincome families. Family Relations, 53, 159-167.

Owen, J. M. (2007). Program evaluation: Forms and approaches. New York: Guilford Press.

Pekrun, R. (2011). Emotions as drivers of learning and cognitive development. In R. A. Calvo \& S. K. D’Mello (Eds.), New perspectives on affect and learning technologies: Vol. 3. Explorations in the learning sciences, instructional systems, and performance technologies (pp. 23-39). New York: Springer Science + Business Media.

Penuel, W. R., Bates, L., Gallagher, L. P., Pasnik, S., Llorente, C., Townsend, E., et al. (2012). Supplementing literacy instruction with a media-rich intervention: Results of a randomized controlled trial. Early Childhood Research Quarterly, 27, 115-127.

Piaget, J. (1954). The construction of reality in the child. New York: Basic.

Reis, S. M., Colbert, R. D., \& Herbert, T. P. (2005). Understanding resilience in diverse, talented students in an urban high school. Roeper Review, 27(2), 110-120.

Ringstaff, C., \& Kelley, L. (2002). The learning return on our educational technology investment: A review of findings from research. San Francisco, CA: WestEd Regional Technology in Education Consortium. Retrieved September 27, 2006 from http://www.wested.org/online_ pubs/learning_return.pdf

Rutter, M. (1990). Psychosocial resilience and protective mechanisms. In J. Rolf, A. S. Masten, D. Cicchetti, K. H. Nuechterlein, \& S. Weintraub (Eds.), Risk and protective factors in the development of psychopathology (pp. 181-214). Cambridge: New York, NY.

Seccombe, K. (2002). "Beating the odds" versus "changing the odds": Poverty, resilience, and family policy. Journal of Marriage and Family, 64, 384-394. 
Seinfeld, J. (1989). Therapy with a severely abused child: An object relations perspective. Clinical Social Work Journal, 17(1), 40-49.

Sesame Workshop. (1983). Community education services at Sesame Workshop [Brochure]. New York: Author.

Shure, M. (2000). I can problem solve. An interpersonal cognitive problem-solving program (preschool). Champaign, IL: Research Press.

Silverman, R., \& Hines, S. (2009). The effects of multimedia-enhanced instruction on the vocabulary of English-language learners and non-English-language learners in pre-kindergarten through second grade. Journal of Educational Psychology, 101, 305-314.

Uchikoshi, Y. (2006). English vocabulary development in bilingual kindergarteners: What are the best predictors? Bilingualism: Language and Cognition, 9, 33-49.

Waxman, H. C., Lin, M.-F., \& Michko, G. M. (2003). A meta-analysis of the effectiveness of teaching and learning with technology on student outcomes. Naperville, IL: Learning Point.

Webster-Stratton, C. (2002). Effective classroom management skills training and dina dinosaur's social skills and problem-solving curriculum training for the classroom: Leader's guide. Seattle, WA: Incredible Years.

Werner, E. E., \& Smith, R. S. (1992). Overcoming the odds: High risk children from birth to adulthood. Ithaca, NY: Cornell University Press.

Wingspan, L. L. C. (1999). Al's pals: Kids making healthy choices. Richmond, VA: Author.

Woltmann, A. G. (1940). The use of puppets in understanding children. Mental Hygiene, 24, $445-458$.

Wright, J. C., Huston, A. C., Murphy, K. C., St. Peters, M., Pinon, M., Scantlin, R., et al. (2001). The relations of early television viewing to school readiness and vocabulary of children from low-income families: The early window project. Child Development, 72, 1347-1366.

Yotive, W., \& Fisch, S. M. (2001). The role of Sesame Street-based materials in child-care settings. In S. M. Fisch \& R. T. Truglio (Eds.), "G" is for growing: Thirty years of research on children and Sesame Street (pp. 181-196). Mahwah, NJ: Lawrence Erlbaum Associates.

Zielinska, I. E., \& Chambers, B. (1995). Using group viewing of television to teach preschool children social skills. Journal of Educational Television, 21, 85-99. 